\title{
La Educación Sexual Integral será feminista o no será
}

\section{Verónica Fulco}

La educación sexual está en boca de todxs por estos días. Hasta quienes históricamente se han opuesto a ella, hoy la reclaman como estrategia preventiva para no llegar a un aborto o para ocultar más o menos explícitamente que prefieren legislar en contra de su legalización, aun si eso les sigue costando la vida a las personas gestantes en nuestro país.

No obstante, no debemos engañarnos: deberíamos desconfiar de la existencia de un acuerdo en relación con lo que entendemos por educación sexual.

Hace unos años, cuando se debatió la actual Ley $26.150^{1}$, uno de los argumentos que circulaba frente a quienes se oponían a ella era que educación sexual ha habido siempre y seguirá habiendo. Tácita o explícita, debatida socialmente o no, socialmente justa o responsable de producir oprimidxs y opresorxs, todxs hemos recibido y seguiremos recibiendo en la escuela y por parte de otras agencias de socialización una educación sentimental determinada, un modo de relacionarnos con nuestros cuerpos y con los de lxs otrxs, una forma de vincularnos con nuestra salud, de entender las relaciones, los afectos, de vivir las pasiones, los deseos, los placeres. Por supuesto, en el campo de la sexualidad como en otras esferas de la vida humana, los discursos están jerarquizados y algunos resultan hegemónicos en un momento y lugar dados. El debate para entonces no era si educación sexual sí o educación sexual no, sino qué educación sexual. Y podríamos arriesgar que el solo hecho de haber dado el debate supuso un movimiento de resistencia en condiciones históricas de disputarle el lugar a la perspectiva que hasta entonces había resultado dominante: la mirada cisheteropatriarcal.

Así queda al menos parcialmente de manifiesto en el propio texto de la ley, en algunos de los objetivos que explícitamente se propone (como el de "procurar igualdad de trato y de oportunidades para varones y mujeres") o en el marco normativo en que se encuadra ${ }^{2}$.

No obstante la existencia de una ley por sí misma, por más maravillosa que sea, no sirve para garantizar una transformación de las conciencias, un cambio en los paradigmas culturales, un ejercicio pleno de los derechos que aquella viene a garantizar. Para que todo esto tenga lugar se necesitan políticas públicas concretas que operativicen los principios plasmados por escrito; se necesitan actores sociales en lugares estratégicos que lleven adelante dichas políticas; se necesitan mecanismos de evaluación de estas políticas que a su vez efectivamente retroalimenten las prácticas de implementación de la normativa, cualquiera sea esta; y se necesita una ciudadanía que se apropie y le dé vida a esa letra plasmada en papel.

1. Esta ley, sancionada el 4 de octubre de 2006, crea el Programa Nacional de Educación Sexual Integral.
2. (Ley 25.673 de creación del Programa Nacional de Salud Sexual y Procreación Responsable; Ley 23.179 de ratificación de la Convención sobre la Eliminación de todas las Formas de Discriminación contra la Mujer; etcétera) 


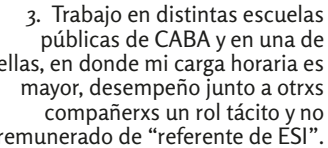

\section{El contexto}

No se puede pensar una ESI sin pensar en el contexto histórico-político en el que se inscriben sus prácticas pedagógicas. Por lo tanto, hablar de ESI hace unos años o en la actualidad implica una distancia enorme porque cultural y políticamente ha habido muchos movimientos. Por un lado, el cambio de gobierno a partir de 2015 ha facilitado y/o promovido un clima en el que los discursos de derecha, tradicionalistas, fachos incluso, han resurgido con fuerza de entre las sombras y gozan de cierta legitimidad social. En paralelo a eso y casi contradictoriamente el movimiento de mujeres, el movimiento feminista y el movimiento LGTBIQ han crecido en fortaleza, en presencia dentro de la sociedad, se han masificado incluso, aun si todavía no podemos esgrimir qué supone exactamente esa masificación en términos de la naturaleza de los contenidos que han impulsado históricamente esas luchas. Aunque lo celebro, tengo la sospecha de que hay cierto vaciamiento ideológico o cierta fagocitación por parte del sistema en el hecho de que esos movimientos se hayan vuelto multitudinarios; que el sentido de algunos de sus planteamientos se haya lavado un poco. Es común hoy pasar por un negocio cualquiera de ropa y que haya una remera con la palabra "feminista" en el frente. ¿Quiénes compran esa remera? ¿Por qué la compran? ¿En qué medida la persona que usa esa prenda conoce sobre teoría feminista o adscribe a sus postulados? ¿En qué medida hace de lo personal algo político? Es un poco como lo que sucede con la remera del Che...

A esta presencia masiva del feminismo, del movimiento de mujeres y del de la disidencia sexual debemos sumarle (y/o reconocerle) algunas conquistas recientes como haber logrado el reconocimiento de la figura de travesticidio en el juicio por el asesinato de Diana Sacayán o la media sanción de la ley de aborto legal, seguro y gratuito. A la vez podríamos arriesgar que es el ejercicio de estas mismas luchas el que ha posibilitado que estos movimientos se difundan y se popularicen.

El grado de visibilidad social que han adquirido los movimientos mencionados así como los debates que vienen ganando estado público permean, sobre todo, en las nuevas generaciones. Conviven así en la escuela discursos conservadores, sobre todo por parte de lxs adultxs, con jóvenes que toman colegios en reclamo de ESI, que llevan en sus mochilas atado el pañuelo verde, que adquieren un nuevo protagonismo en materia de participación política y en relación a la concepción de "política" que manejan, ya que la política nacional, partidaria, tradicional no logra interpelarlxs del modo en que lo hace la política sexual.Y esto es así, entre otras cosas, porque estos sujetos han podido comprender que la política sexual lxs toca bien de cerca en sus vidas cotidianas, algo que no sucede con otros temas, como por ejemplo la lucha en defensa de la escuela pública. Con excepción de aquellas instituciones educativas que cuentan 
con centros de estudiantes fuertes y con trayectoria, la mayoría del estudiantado no percibe el reclamo de paritarias docentes como una demanda propia o con la que claramente deberían solidarizarse. ¿Qué ha hecho posible que lxs jóvenes se apropien de una serie de demandas más que de la otra? Posiblemente haya sido el hecho de que habitualmente se conciba lo político en términos sumamente restringidos y que, además, se piense como no deseable -al menos en estos tiempos- politizar el aula. Por eso, los avances en materia legal en torno a la ESI y los intentos de implementar dicha ley, posiblemente hayan contribuido a que socialmente se haya ido visibilizando que la sexualidad y las identidades no nos son dadas por el azar ni por puro determinismo biológico, sino que son el producto de un entramado de dispositivos de adoctrinamiento y control que las moldean. Es decir: planteada como indica la ley, la ESI supone un posicionamiento ideológico muy claro. Propiciar procesos de enseñanza-aprendizaje basados en la ESI conformes a este marco normativo supone hacer política en la escuela.

\section{Lxs destinatarixs}

En este escenario, una deuda pendiente consiste en entender quiénes son lxs educandxs, quiénes son esxs sujetxs que habitan las aulas en la actualidad. En cualquier práctica de enseñanza-aprendizaje es fundamental tener en cuenta quiénes son nuestrxs interlocutorxs para a partir de allí tomar decisiones adecuadas en lo pedagógico. La ESI no es la excepción en ese sentido y a mí, personalmente, se me hace un poco imprecisa esa imagen. Dicha imprecisión, de hecho, posiblemente obedezca a que estamos en un momento de transición, en donde ese sujeto es un ser que está deviniendo.

Sin embargo, podemos hacer algunas afirmaciones. Por ejemplo, que aun para una persona que tiene años de trabajar estas temáticas y cuya formación pasa principalmente por el activismo y por el desaprendizaje constante de las propias prácticas patriarcales naturalizadas, el encuentro con este sujeto adolescente no es un encuentro fácil. Muchas veces nuestras miradas y nuestras propuestas resultan un tanto obsoletas y nos encontramos también con una serie de cuestionamientos que nos obligan a hacernos nuevas preguntas, a las que aún no habíamos llegado. Porque pertenecemos a una generación que necesita deconstruir determinados modelos en base a los cuales ha sido socializada, mientras que las nuevas generaciones directamente irrumpen en el mundo desde otro paradigma.

Ilustremos esto aunque no usemos los nombres reales. Lisa está en primer año y pide que lo nombren en masculino y que lo lean varón, pero que respeten su nombre actual. Fer, por su parte, está en cuarto año y una profe que suele tener buen vínculo con lxs estudiantes detecta que posiblemente se asuma trans. Para darle un espacio donde poder hablar al respecto en caso de necesitarlo o desde donde legitimar la identidad que haya escogido, sea cual fuere, le pide tener una charla. En ella, Fer es muy clarx: "Yo soy Fer, ¿por qué tengo que definirme de alguna otra forma? ¿Para la tranquilidad de otres?". A Fer no le interesa ser pensadx en función de las categorías varón/mujer, ni cis/trans, y entiende que esas etiquetas no deberían suponer ninguna diferencia en su vida.

Las identidades de nuestrxs estudiantes muchas veces estallan todos los modelos que conocemos y se inscriben en una línea que escapa a los encasillamientos, sea porque no hay definición que les calce o porque conciben la identidad como algo móvil.

Tampoco sus modelos vinculares son necesariamente los modelos con los cuales nos peleamos nosotrxs. Sin duda forman parte de una cultura, con una serie de canciones, 
4. Hace poco una estudiante me preguntó frente a todo el curso, luego de explicar cómo se hacía y se usaba un campo de látex, si yo lo había usado para hacerle sexo oral a alguna mujer. Me sonreí y les dije que no hablaría de mi vida privada. Entonces saltaron varixs chicxs, en tono de broma, a decir que $\mathrm{mi}$ sonrisa y mi silencio me delataban, que seguro era que sí lo había hecho. Me reí y seguí con la clase. películas, historias que circulan y que giran en torno a las mismas ideas de amor romántico como ideal amatorio con el que fuimos socializadas otras generaciones. No obstante basta hablar con lxs adolescentes para encontrarse con que hay muchas cuestiones que nos diferencian: la mayoría descree o ni piensa en un amor "para toda la vida", muchxs no entienden a qué nos referimos cuando le hablamos del mito del "amor verdadero"; la monogamia también goza de menos estima o, al menos, el poliamor no les resulta en absoluto descabellado, lo encarne quien lo encarne; al menos en un plano discursivo, tienen clarísimo el tema del consentimiento en las relaciones, y asumen que la heterosexualidad no es ni la única orientación sexual posible, ni la correcta. Con esto, no quiero decir que no imperen ciertas concepciones del modelo de amor romántico en las juventudes, pero claramente opera de otro modo; modo que habría que explorar. También hay mucho menos tabú para hacer y decir ciertas cosas y eso lleva a que se generen situaciones que a algunxs docentes lxs dejan en offside. Por ejemplo, estudiantes varones que van a clase con las uñas o los labios pintados, estudiantes que te hacen preguntas sobre tu propia sexualidad ${ }^{4}$, estudiantes que te piden hablar concretamente de prácticas sexuales desde una perspectiva centrada en el placer. Y acá hay todo un punto, porque parte del abordaje que propone la actual normativa se centra justamente en dejar de pensar la sexualidad como un peligro del que hay que enseñar a cuidarse: evitándolo, lisa y llanamente, o previniendo sus posibles (y negativas) consecuencias: las ITS y los embarazos. Recordemos sobre este punto que hay una mirada adultocéntrica hegemónica que, en la adolescencia, no distingue entre embarazos deseados y no deseados, y que sostiene que en esta etapa de la vida lo mejor para esxs jóvenes es no tener que asumir la responsabilidad de criar unx hijx. Responder a estas demandas específicas de lxs estudiantes, no obstante, que se inscriben perfectamente dentro del marco de sus derechos, supone otro trabajo pendiente por parte del mundo adulto.

Por último, cuando pienso en el perfil de nuestrxs estudiantes, me pregunto también dónde están las estudiantes travestis, por qué no tenemos estudiantes travestis en nuestras aulas. En ninguna de las escuelas donde trabajo, al menos. En los últimos años he visto empezar a visibilizarse a estudiantes gays, a estudiantes lesbianas y bisexuales, y recientemente a sujetos trans (sobre todo varones), pero todavía no he logrado ver a las travestis en nuestras aulas. Como así también cuesta ver docentes que pertenezcan al colectivo LGTBIQ y que sean visibles en sus lugares de trabajo.

\section{Perfiles docentes y capacitación}

Así como lxs jóvenes con sus prácticas estallan muchas veces las etiquetas conocidas, así también el discurso conservador imperante se disfraza de políticamente correcto para señalar que dichas etiquetas son estigmatizantes o que, para garantizar la igualdad de derechos, lo mejor es reconocer que "ante todo, somos personas". Eso afirmó una docente cuando estábamos armando el acto del 17 de mayo contra el lesbo/ homo/bi/travesti/trans-odio. Decía no entender por qué seguíamos remarcando las diferencias, mientras que otra profesora pidió el micrófono en plena actividad a fin de poder decirle a lxs estudiantes heterosexuales que se quedaran tranquilxs, que todxs teníamos los mismos derechos y que por lo tanto si ellxs eran heterosexuales también estaba bien, que no permitieran que nadie quiera convencerlxs de ser algo que no son (¿’). De más está decir que nadie había intentado convencerlxs de otra cosa.

Esto nos lleva a la cuestión de los perfiles docentes y la ESI. Hay una demanda generalizada y al mismo tiempo tácita que exige que todxs lxs docentes trabajen la ESI de manera transversal. En algún momento se decía que en la medida en que todxs tenemos una sexualidad, vínculos, un cuerpo, etc. cualquier adultx podría acompañar 
a lxs más jóvenes a reflexionar sobre cuestiones afines. El primer problema de esta posición es que muchas veces se restringe la ESI a una serie de temas cuando en realidad la ESI es, por sobre todo, una perspectiva, un modo de mirar. Decíamos más arriba que educación sexual ha habido siempre pero que la cuestión pasa por qué educación sexual queremos. El paradigma de la Educación Sexual Integral que está plasmado en la normativa vigente se distingue por su posicionamiento ideológico: se trata de una educación sexual integral y con perspectiva de género. Entonces, tenemos por un lado a docentes que no están debidamente formadxs para llevar adelante esa perspectiva en el trabajo en el aula (o fuera de ella) o que no adscriben políticamente a sus planteamientos $y$, desde ese lugar -aunque tácitamente también-, actúan como objetorxs de conciencia o trabajan una educación sexual que no se circunscribe a lo establecido por la ley.

La docencia supone un lugar de poder, sean los sujetos que encarnan ese rol conscientes de ello o no. Por un lado, porque cuando unx docente logra conectar con sus estudiantes, tiene una capacidad multiplicadora de prácticas, discursos, herramientas, sean estas afines a la libertad y al pensamiento crítico, o funcionales a un sistema de opresión determinado. Por otro lado, el lugar de lxs maestrxs y profesorxs es estratégico también porque en muchas instituciones existe la autonomía de aula; es decir, que lxs docentes pueden hacer en el aula "la gran revolución"5.

Por lo mismo entonces, no es posible que cualquierx docente trabaje la ESI. Porque no se trata de decir cualquier cosa en torno a la sexualidad, ni de dar nuestra opinión al respecto, sino que se trata de dar información veraz, pertinente, actualizada, científicamente comprobada, confiable y en el marco de los derechos reconocidos por la normativa vigente. Así, por ejemplo, unx docente no debería poder hablar en el aula en contra del aborto, o del divorcio, o del matrimonio igualitario, o de lxs travestis, o de lxs judíxs, porque cualquiera de estas posiciones supone cuestionar las leyes actuales o derechos reconocidos por estas. Hay otras situaciones que suelen darse, quizás más sutiles, en donde también se promueven valores contrarios a los que promueve la Ley 26.150, y que tienen lugar por la formación ideológico-pedagógica de lxs docentes en torno a la educación sexual. Por ejemplo, hace poco, en un consejo de convivencia, una profesora quiso convencer a una estudiante de que intentábamos ayudarla genuinamente (y no juzgarla o castigarla como ella suponía). Para ello, le dijo: "Vos que sos mujer, ¿qué harías si ves a un niño que está en peligro o que está haciéndose daño? ¿No intentarías cuidarlo acaso?”. Debíamos ser por lo menos cinco o seis adultxs en ese consejo. A nadie más que a mí le hizo ruido el "vos que sos mujer" en esta intervención. De hecho, otrxs docentes utilizaron la misma frase durante dicho consejo.

Hablemos entonces de capacitación docente. Básicamente, en lo que a educación sexual respecta, tenemos tres perfiles de formación: a) la que se da a través de instituciones formales, cursos virtuales y presenciales, de grado y de posgrado, postítulos, con puntaje y sin puntaje; b) la que viene del ámbito del activismo feminista; c) la que viene de otros espacios políticos y/o de socialización y que, en general, no se alinea con los postulados que estipula la normativa en la materia.

Sin embargo, es interesante pensar que no está habiendo mecanismos de reconocimiento de los saberes provenientes del activismo feminista (salvo que estxs profesionales a su vez hagan alguna capacitación en instituciones formales) y que pese a que es de este campo de donde surgen lxs docentes más comprometidxs con los objetivos que persigue la ESI y quienes están, muchas veces, mejor formadxs (porque la perspectiva de género no es algo que pueda adquirirse de la noche a la mañana, ni tomando un curso de tres meses, si no que demanda cuestionarse la propia vida), esxs docentes no cuentan con titulaciones y podrían ser desplazadxs por otrxs con
5. Expresión tomada de un testimonio del documental "La Educación Prohibida". 
menor experiencia y formación (en sentido amplio) de los puestos que se creen en torno a los proyectos institucionales de cada establecimiento (o incluso a nivel gubernamental) para implementar la ESI. Acá hay una situación que, al menos, merece ser analizada con más detenimiento.

¿Por qué afirmamos que la perspectiva de género no se adquiere tan fácilmente? Yo puedo leer mucha teoría al respecto. Puedo también tener un discurso impecable. Pero si mis posturas en la vida, en la cotidianeidad, no son coherentes con esos postulados, es factible que en alguna medida fallen mis análisis, que no pueda detectar algunos emergentes a trabajar en la escuela, que naturalice algunas cuestiones.

No obstante es imperioso que cada vez más docentes adquieran esas herramientas, porque todo docente debería intervenir en la institución de manera coherente con los lineamientos que plantea la ley y la misma estipula que el abordaje de la ESI es transversal. Es decir, excede el trabajo en el marco de una asignatura específica (aunque personalmente no descartaría esta opción como una línea de trabajo más dentro de cada escuela). Y lo excede, entre otras cosas, porque los emergentes sobre los que habría que intervenir pueden aparecer en cualquier momento. Si un estudiante insulta a otro llamándolo "puto", lx adultx que fuera debería poder hacer una buena intervención desde la ESI y no dejar pasar estas situaciones, naturalizándolas. Porque cada vez que no se interviene de forma explícita, se está interviniendo de manera implícita en la dirección opuesta.

\section{Palabras finales}

Doce años de ESI, aún si su implementación no ha sido sistemática, necesariamente han servido para plantar ciertas semillas en una generación que creció escuchando cosas que antes eran tabú, concibiendo como tangenciales algunas cosas que antes se pensaban como fijas e inamovibles, y entendiendo como derechos legítimos lo que antes podía ser leído socialmente como desviaciones o prácticas aberrantes. Una generación que por ende es tierra mucho más fértil para los debates que se están dando en la actualidad. Dos líneas de acción (las políticas implementadas en el marco de la educación formal y la disputa de sentido en la esfera pública) promovidas desde sectores afines en lo ideológico que se intersectan y hacen mella en estas generaciones jóvenes. 